Nepalese Vet. J. 35:134- 141

\title{
Welfare Status of Indigenous Cattle in Terai and Mid-Hill of Nepal
}

\author{
K. P. Rana ${ }^{1 *}$, K. Kaphle ${ }^{2}$ and G. Gautam ${ }^{1}$ \\ ${ }^{1}$ Agriculture and Forestry University, Chitwan, Nepal \\ ${ }^{2}$ Institute of Agriculture and Animal Science, Tribhuwan University, Nepal \\ *Corresponding author: bkpramod90@gmail.com
}

\begin{abstract}
The aim of present study was to assess the status of welfare of indigenous cattle, based on certain animal-linked parameters: body condition (BCS), body hygiene (cleanliness), lameness, skin injuries, general condition, and flight distance. The study was ruled in eight herds (10 cows /herd) in Terai and Mid-hill region of Nepal from March to June 2014. Altogether 80 cattle kept in semi-intensive system were assessed using several indicators determined through specific methods. Out of 80 cattle, $2(2.5 \%)$ had BCS between 1.5-2, considered as very thin cows; 49 (61.25\%) had BCS between 2.25-2.75, considered as thin cows; 29 (36.25\%) had BCS 3-3.75 considered as normal cows and no cows found with BCS more than 3.75 score; 69 (86.25\%) had dung particles at their lower legs, 60 (75\%) had dung particles at their flank region and $11(13.75 \%)$ had dung particles at their udder region; $4(5 \%)$ were moderately lame, 27 (33.75\%) had hairless spot on their different body parts(hock, knee joints, neck), 15 (18.75\%) had swelling joints (knee joints); 10 (12.5\%) showed fear at the observer's approach. The general condition was good of all the assessed cows. The obtained results indicate that more than half of the assessed cows are thin and dirty which has a negative impact on their health and welfare. The main factors that affect the indigenous cattle welfare in Nepal are insufficiency of feeding, poor housing system, poor sanitation and hygiene maintenance, lack of treatment of injured/diseased cattle and somewhat poor human animal relationship.
\end{abstract}

Keywords: BCS, Dirty, Fear, Housing, Indigenous cattle, Lameness, Welfare status

\section{INTRODUCTION}

In Nepal, there are 7.2 million cattle (Statistical information of Nepalese Agriculture, 2012), among them $88 \%$ are indigenous and remaining are exotic. Nepali indigenous cattle are small sized and humped (Bos indicus). They are disease resistant and hardy in nature. They can survive in scarce condition without supplement of extra concentrate ration. They prefer grazing in the forests or rangelands where they can get green forage and fodders and medicinal plants as well. Although their milk production is low, they are very useful in many aspects for us. Hindu people worship 
them as a form of goddess Laxmi. Their products like milk, milk fat, urine and dung have high medicinal value for the treatment of many diseases like, diabetes, asthma, cancer and many diseases of respiratory system. Their milk is used as panchamrit/ pure liquid given after religious celebration (Pathak et al., 2003). The local price of urine, milk, and fat of these cattle is Rs. 300/litre, Rs.100/litre and Rs.1000/kg respectively which is too higher than the price of improved dairy cattle products (Guru, S., 2014). It has been found that their urine contains curcumin, the anti-cancer element so homeopathic pharmaceuticals are using it in their medicines, and it is not found in humpless improved dairy cattle's urine (Dixit, R., 2015). Their milk is rich source of vitamins and minerals with less cholesterol and used in the treatments of constipation. Their milk fat is useful in the treatment of asthma, sinus, common cold, snoring sound etc and for massage. Their dung and urine act as anti-bacterial so used to purify the houses and religious places in religious activities (Guru, S., 2014). But nowadays their number is decreasing day by day due to commercialization of dairy sector. Due to their low productivity, farmers are neglecting them and leaving them to the roadsides. Some hermitage and marginalized communities only keep the indigenous cattle and their poor economic condition is reflected in poor wellbeing of the cattle. They are not given nutritious feed, no specific treatments on diseased and injured condition, no deworming, no good housing and feed deficit due to deforestation and decreasing rangeland areas which are being invaded by alien species of plants and being covered by human waste materials. So, all these cause the decreased welfare condition of the indigenous cattle in Nepal.

"Welfare principally concerns both the physical and psychological wellbeing of an animal, which is largely determined by the standard of stockman ship, the system of Husbandry and the suitability of the animal for the environment" (Farm Animal Welfare Council, 2009). Nowadays the dairy cattle welfare represents a permanent concern in many countries due to the impact on animal health and productivity and ultimately upon public health (Broom, D. M., 1991).Traditionally, farm animals' welfare assessment has focused on the measurement of resources provided to the animal such as housing and its design criteria (Capdeville et al., 2001). Later on, it was modified on animal-related parameters, such as body condition score (BCS), body cleanliness, lameness, skin lesions, injuries and swellings, animal human relationship and so on which provides exact welfare condition of farm animals, (Winckler et.al., 2002). So, the aim of this research was to assess the welfare condition of indigenous cattle of Central Terai and Mid-hills of Nepal, to know the major welfare parameters which are in very low condition or decreasing the welfare and range dynamics of that regions affecting the feed availability to them, so that future strategy to increase their welfare condition can be made to conserve them to increase to their production. 


\section{MATERIALS AND METHODS}

The study was conducted on Bageswori cattle conservation centre, Devght, Chitwan, in Terai and Mrighsthali cattle conservation centre, Pashupatinath kshetra, Kathmandu and Ramdi cattle conservation centre, Ramdi, Shyanjha in mid-hills of Nepal, from February to June 2014. The welfare of these cattle was assessed on the basis of several animal-linked parameters such as; body condition score (BCS), body Cleanliness, lameness, injuries, flight distance etc. Among 80 indigenous cattle, each cow was examined and evaluated by two expert examiners. For the assessment of some parameters like (lameness and flight distance) the cows were untied and moved outside the shed.

The body condition score (BCS) and cleanliness scoring was assigned according to the system elaborated by Vasseur et al., (2013) with scores from 1 to 5. Thus, a fat cow is one with $\mathrm{BCS} \geq 4$; a normal cow is one with $\mathrm{BCS} 3-3.75$; a thin cow is one with BCS 2.25-2.75 and an emaciated/very thin cow is one with $\mathrm{BCS} \leq 2$. For cleanliness manure contamination in three body regions: udder, flank and leg were observed. The skin lesions (mainly knee joints left, right; hock joints left, right and neck region) and lameness were assessed through the method proposed by Gibbons et al., (2012). The general condition was established using the method proposed by Thomsen, et al., (2006) as unaltered, slightly modified or severely modified. Flight distance was appreciated through observation and measuring the distance (in meters) to how close we could approach the cow before it retreats from us (Leeb et al., 2004). In order to determine the avoidance distance, the cows were untied and moved outside the barn. The participant in the test waited at a distance of 3 to $4 \mathrm{~m}$ for the cow to look at him before approaching, i.e. more or less directly from the front, walking slowly looking at the cow without direct eye contact, and keeping arms and hands close to the body. We considered that the cows do not show fear when the avoidance distance is smaller or equal to $1 \mathrm{~m}$ and that the cows show fear when the avoidance distance was more than $1 \mathrm{~m}$. We visited all the rangelands and forests (upto $500 \mathrm{~m}$ inside) in Terai and Mid-hill region where they were taken to graze to know their conditions.

\section{RESULTS}

After assessment of 80 indigenous cattle, the lowest condition of major animal welfare parameters were found that $2(2.5 \%)$ cows had lowest BCS between 1.5-2 which were considered as very thin cows; $15(18.75 \%)$ had skin injuries with wound (major swelling on joints and neck region); $4(5 \%)$ were moderately lame but unable to run and $10(12.5 \%)$ showed fear at the approach of the examiner. The general condition of all the cattle $80(100 \%)$ was found to be normal. Above data are shown in Figure 1. 


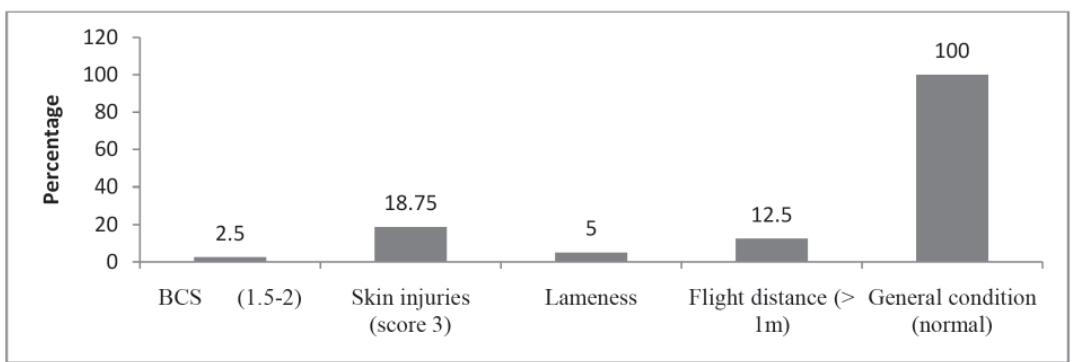

Fig. 1: Bar graph showing condition of major parameters of five freedoms of indigenous cattle in Central Terai and Mid-hill of Nepal.

The detailed distribution of the BCS scores has been shown in fig 2. It was found that $2(2.5 \%)$ cows had BCS between 1.5-2 considered as very thin cows; 49 (61.25\%) cows had BCS between 2.25-2.75, considered as thin cows; 29 (36.25\%) had BCS between 3-3.75, considered as normal cows but no cattle had BCS more than 4, considered as fat cows.

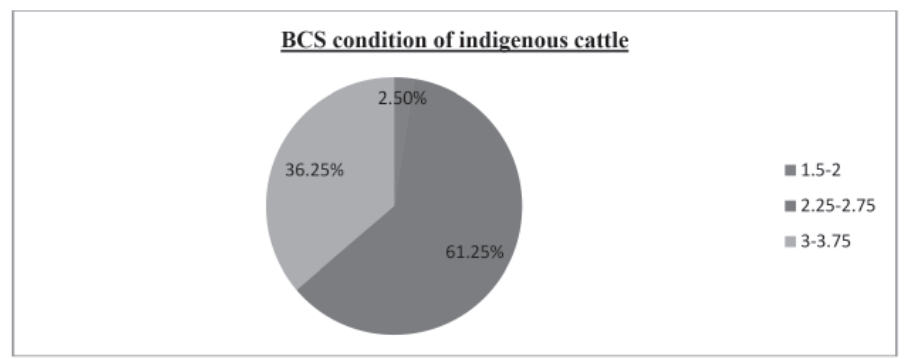

Fig. 2: Pie-chart showing detailed distribution of BCS of all assessed indigenous cattle.

The detailed condition of scores of body cleanliness at the level of three evaluated body areas was found that $69(86.25 \%)$ had dirty lower legs, $60(75 \%)$ had dirty flank and $9(11.25 \%)$ had dirty udder region. The data are shown in fig.3

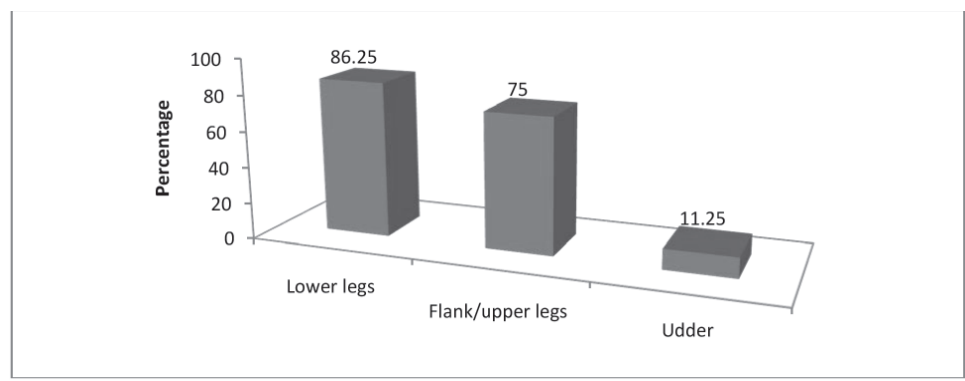

Fig.3: Bar graph showing scores of cleanliness of all assessed indigenous cattle. 
The condition of injuries has been shown in fig 4. It was found that $27(33.75 \%)$ cows had hair less spots or lesion on bald area of different body parts mainly at joints and neck, shoulder region; 15 (18.75\%) had swelling joints with wound.

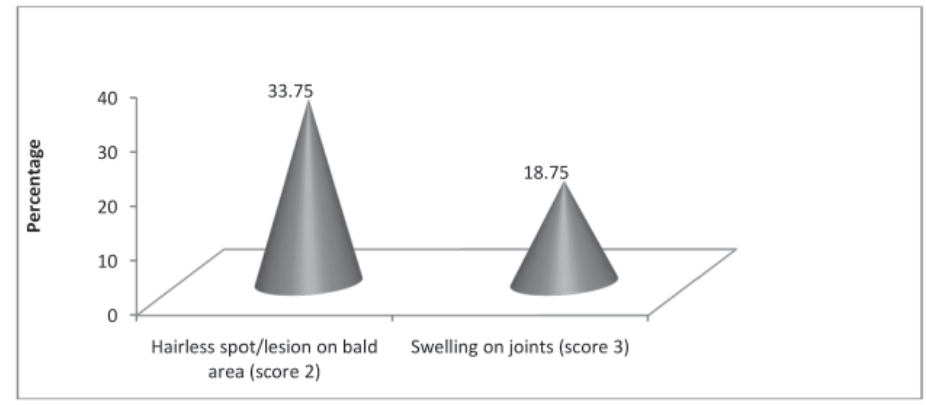

Fig. 4: Bar graph showing injuries condition in all assessed indigenous cattle.

The condition of rangelands and indigenous cattle in different regions of Terai and Mid-hill are presented in photos 1 to 8 . It was found that most of their grazing land was occupied by alien species of plants like Parthenium hysterophorus, Lantana camera, Eupatorium adenophorum, and Pteridium roxburghii. While forests are invased by Michania micrantha. At the same time those grazing areas as well as forests were also found full of human origin wastes like plastics and garments. All these conditions showed that they are deprived of nutrition, good housing and cleanliness which finally state their compromised welfare.

\section{DISCUSSION}

In our study, most of the cattle (61.25\%) were found to have BCS 2.25-2.75 which were categorized as thin cows. While very thin cows having BCS $\leq 2$ were found to be $2.5 \%$ which satisfies the welfare critical points criteria described by Grandin T. (2011). The similar findings were obtained by Gudaj, R.T. (2013) who found $4.37 \%$ and $4.19 \%$ cows with BCS $\leq 2$ in 25 farms of Hungey in 2010 and 2011 respectively. While Popescu et al., (2010) had found 56.45\% cattle of BCS less than 2 in the farm of Romania. The higher number of thin cows in our study might be due to the forage deficiency in their grazing area which was found covered by alien species of plants and human origin plastic wastes.

In our study, the cattle with hair losses mainly in hock, knee joints were found to be $33.75 \%$, the similar was found by whey et al., 2003 in UK. i.e. $29.1 \%$. Some lesser percent was found by Gudaj, R.T. (2013) in Hungery, who found $11.66 \%$ and $14.09 \%$ dry cow and lactating cow having hair losses in legs and Popescu et al., (2010) found $14.38 \%$ cattle with hair loss or skin lesion in the farms of Romania. The more the hair losses condition in leg in cattle might be due improper bedding and floor type. 
In our study, hock-knee lesions were found to be in $18.75 \%$ cows which was similar with the findings of Gudaj R.T. (2013) who found $15.28 \%$ and $16.75 \%$ dry cattle and $18.24 \%$ and $23.03 \%$ lactating cattle with hock and knee lesions. While Whey et al., (2003) found $27.2 \%$ hock knee lesions in his research in UK. Hock- knee lesion might be arisen due to improper bedding and less-cleanliness of the shed, which favors the skin sloughing and then bacterial contamination in these parts.

In our study $5 \%$ cattle were found to be moderately lame which is similar to the findings of Popescu et al., (2010) who found 4.86\% lame dairy cattle in 52 dairy farms of Romania. But disagrees with Haskell et al., (2006), Huxley et al., (2004), Rutherford et al., (2009) and Gudaj R.T. (2013) who found $24.3 \%, 19 \%, 34 \%$ and $35.39 \%$ clinically lame respectively in dairy farm of Hungery. Lameness is caused by poor management; low quality feed supplement and genetic combination of the animal. The lesser no. of lame cattle in our study might be due to hardy nature of indigenous cattle which produce less milk and so need less energy and minerals for their body maintenance.

Our study found $86.25 \%, 75 \%$ and $11.25 \%$ dirty cattle at lower legs, flank region and at udder region which was more than the findings of Gudaj, R.T. (2013) who found $37.38 \%, 21.85 \%$ and $21.26 \%$ dirty dry cattle at lower legs, flank region and udder region respectively in the farm of Hungery. Whay et al., (2003) found 47.4\%, 10.7\% and $22.2 \%$ respectively in UK. And Popescu et al., (2010) found 11\%, 19\% and 14\% respectively in the farms of Romania. The higher number of dirty cows might be due to less number of manpower in these religious farms to clean the shed and groom the cattle regularly and were kept more in a single shed.

In our study only $12.5 \%$ of the assessed cattle showed fear at the approach of examiner. Similar was found by Popescu et al., (2010) i.e. $14.59 \%$ cattle showed fear in the farm of Romania. The smaller number of cattle showing fear indicates good human-animal relationship and which was due to religious concept of owners toward these cattle in our context. The general condition of these cattle was found as unaltered which is like the findings of Popescu et al., (2010).

\section{CONCLUSION}

The greatest and the most frequent deviation from normality was found in BCS and cleanliness. So, feed deficit and poor housing and sanitation system was analyzed as the major factor or parameter leading to compromised welfare condition of these indigenous cattle, causing the decrease in their number and production. Their grazing area were found largely invased by alien species of plants like Parthenium hysterophorum in Bageswari region of Central Terai, by Lantana camara and Pteridium acquilinum in Mrighsthali region and by little Eupatorium adenophorum in Ramdi region of Mid-hill of Nepal. At the same time human origin wastes particles mostly, the plastics were also found to be thrown in the grazing area of these cattle 
in all three region which all cause feed deficit and increase chances of swallowing foreign materials leading to the decreased welfare.

\section{RECOMMENDATION}

Appropriate fund, knowledge and awareness toward health and sanitation should be given to the Ashram/hermitage by Government to conserve these indigenous cattle. Appropriate housing and appropriate stocking density should be maintained in the shed. Medicinal value of milk, milk fat, urine of these indigenous cattle should be made well known to all. Appropriate strategies should be made to control the invasion of alien species of plants and rules should be made to throw plastics and other waste only in the safe place.

\section{ACKNOWLEDGEMENTS}

The authors are thankful to Hermitage and Guru Siris team for providing information about indigenous terai cattle for the study.

\section{REFERENCES}

Broom, D.M., (1991). Animal Welfare: Concepts and Measurement. J. Anim. Sci., 69: 4167-4175.

Capdeville J., Veissier I., (2001). A method of assessing welfare in loose housed dairy cows at farm level, focusing on animal observations. Acta Agric Scand A Anim Sci 2001, 30: 62-8.

Definition adapted from Farm Animal Welfare Council: Farm Animal Welfare in GB: Past, present and future. October 2009.

Dixit, R., (2015). https://www.youtube.com/watch?v=23djTM_h064.

Farm Animal Welfare Council 1992. FAWC updates the five freedoms. Vet. Rec. 17: 357.

Grandin, T. (2011): Outline of cow welfare critical points for dairies. [www.document] http://www.grandin.com/cow.welfare.ccp.html (accessed 29 January 2012).

Gudaj, R.T. (2013). Study of animal welfare status and lameness in dairy cow herds in Hungery.

Guru, S., (2014). Through personal communication.

Haskell, M.J., Rennie, L.J., Bowell, V.A., Bell, M. J., Lawrence, A.B. (2006). Housing system, milk production, and zero-grazing effects on lameness and leg injury in dairy cows. Journal of Dairy Science, 89: 4259-4266.

Huxley, J.N., Burke, J., Roderick, S., Main, D.C.J., Whay, H.R. (2004). Animal 
welfare assessment benchmarking as a tool for health and welfare planning in organic dairy herds. Veterinary Record, 155: 237-239.

Leeb C.H., Main D.C.J., Whay H.R., Webster, A.J.F., (2004). Bristol welfare assurance programme - cattle assessment. University of Bristol, UK 2004. http:// www.vetschool.bris.ac.uk.

Pathak, M.L. and Kumar, A., (2003). Cow praising and importance of Panchyagavya as medicine. Sachitra Ayurveda, 5: 56-59.

Popescu, S., Borda, C., Dana, C., Razvan, S., Eva, S., (2010). Lazar University of Agricultural Sciences and Veterinary Medicine, Faculty of Veterinary Medicine, Manastur street, no. 3-5, 400372, Cluj Napoca, Romania.

Rutherford, K.M.D., Langford, F.M., Jack, M.C., Sherwood, L., Lawrence, A.J., Haskell, M.J. (2009): Lameness prevalence and risk factors in organic and non-organic dairy herds in the United Kingdom. The Veterinary Journal, 180: 95-105.

Thomsen, P.T., Baadsgaard, N.P., (2006). Intra- and inter-observer agreement of a protocol for clinical examination of dairy cows. Short communication. Preventive Veterinary Medicine, 2006, 75:133-139.

Vasseur E., Gibbons J., Rushen J., Passille A.M., 2012. Development and implementation of a training program to ensure high repeatability of lameness score of dairy cow in animal welfare assessments.

Vasseur E., Gibbons J., Rushen J., Passille A.M., 2012. Development and implementation of a training program to ensure high repeatability of skin injury score of dairy cow in animal welfare assessments.

Vasseur E., Gibbons J., Rushen J., Passille A.M., 2013. Development and implementation of a training program to ensure high repeatability of body condition score of dairy cows in animal welfare assessments. J. Dairy Sci. 96:4725-4737.

Vasseur E., Gibbons J., Rushen J., Passille A.M., 2013. Development and implementation of a training program to ensure high repeatability of cleanliness score of dairy cows in animal welfare assessments.

Whay, H.R., Main, D.C.J., Green, L.E., Webster, A.J.F. (2003): Assessment of the welfare of dairy cattle using animal-based measurements: direct observations and investigation of farm records. Veterinary Record, 153: 197-202.

Winckler C., Bühnemann A. (2002). Social behaviour of commercial dairy herds as a parameter for on-farm welfare assessment. Proc 36th Int Cong ISAE, 2002. 